\title{
Non-contiguous spinal injury: clinical and imaging features, and postulated mechanism
}

\author{
M Silberstein MD, ${ }^{1} \mathrm{~K}$ McLean $\mathrm{MB} \mathrm{BS}^{2}$ \\ ${ }^{1}$ Department of Radiology, Western Hospital, Footscray, Victoria 3011, Australia; \\ ${ }^{2}$ Department of Surgery, Wangaratta Base Hospital, Wangaratta, Victoria 3677, Australia
}

In an attempt to identify possible mechanisms for remote or non-contiguous spinal injury, clinical records and magnetic resonance (MR) images were analysed in 71 consecutive patients admitted for management of acute cervicothoracic spinal trauma. Seven patients $(10 \%)$ were identified with clinical or MR evidence of non-contiguous spinal injury, and either more than one neurological level, or a cord lesion remote from the imaging abnormality. Five of these had radiographic and MRI findings suggesting that the second lesion was due to cord stretching, following local tethering at the first level, including three patients with a small extramedullary haematoma at the site of the distant cord lesion. The other two patients had underlying multilevel degenerative spinal canal stenosis, explaining the second cord lesion. Non-contiguous spinal injury is an infrequent manifestation of acute spinal trauma, and, in contrast to most forms of cord injury associated with spinal trauma, which are due to cord compression, this entity may represent the sequel of cord stretching.

Keywords: spinal injury; non-contiguous (remote) spinal injury; pathophysiology; magnetic resonance imaging; clinical features.

\section{Introduction}

Following trauma to the spine, the resulting spinal cord lesion, in patients with spinal cord damage, usually occurs around the point of impact, with spread over several cord segments above and below this. ${ }^{1}$ Infrequently in closed cord injuries, lesions may be found at more than one level, with one review estimating this number at $15 \%$ of all cord injuries. ${ }^{2}$ The cause of the remote lesion has, in the past, been considered to be the result of secondary or posttraumatic circulatory disorders, ${ }^{3}$ although there have been no published clinical studies on this topic.

Our objective was to attempt to identify possible mechanisms for remote or noncontiguous spinal cord injury using magnetic resonance (MR) imaging in symptomatic patients.

\section{Materials and methods}

The patients included in the study were derived from acute admissions to our spinal injuries unit between 1987 and 1993. For inclusion, patients were required to have a demonstrable cervical or thoracic neurological deficit following spinal trauma, admission to the Austin Hospital Spinal Injuries Unit in Melbourne, Australia, and MR imaging during initial hospital admission. Patients were excluded if they had had spinal surgery in the 12 months following injury or if MR images were not technically satisfactory. Referral bias excluded two patient groups: those in whom deficits were well explained by plain film or CT findings as, at the time, the indications for urgent MR imaging at our institution related to determination of the cause of an unexplained neurological deficit; and those who were extremely ill or too unstable for MR imaging.

Between 1987 and 1993, 71 patients were referred for MR imaging for acute spinal cord injury. At presentation, the patients underwent clinical and radiological assessments. Neurological assessment consisted of determination of neurological level(s) and 
degree of neurological deficit. These assessments were recorded with the pattern type (transverse, anterior cord, central cord, dorsal cord or Brown-Séquard) independent of the radiological findings.

MR imaging was performed on a $0.3 \mathrm{~T}$ resistive MR unit (B3000, Fonar, Melville, New York) on 36 patients and on a $1.5 \mathrm{~T}$ superconducting MR unit (Magnetom 63, Siemens, Erlangen, Germany) on 31 patients. Imaging parameters (imaging planes, pulse sequences, slice thickness and slice intervals) were based on accepted practices. ${ }^{4}$ The spinal cord in each patient was analysed for the presence of: transection- partial or complete discontinuity on sagittal images; haematoma-focal high signal on T1-weighted images or low signal on T2weighted images; contusion-focal high signal on T2-weighted images; and oedema-diffuse high signal on T2weighted images, based on the accepted definitions described in the literature. ${ }^{5}$ The presence of bony injuries (fractures or dislocations), ligament injury, disc protrusions and extramedullary haemorrhage was also recorded, based on accepted definitions. ${ }^{4}$

Non-contiguous spinal injury was defined as the presence of either: more than one demonstrable clinical neurological level of

Table I Clinical and imaging findings in patients with non-contiguous injuries

\begin{tabular}{|c|c|c|c|c|}
\hline Number & Mechanism & $\begin{array}{l}\text { Imaging findings at } \\
\text { upper lesion }\end{array}$ & $\begin{array}{l}\text { Imaging findings at } \\
\text { lower lesion }\end{array}$ & Clinical findings \\
\hline 1 & $\begin{array}{l}\text { Assault: stabbed } \\
\text { in neck }\end{array}$ & $\begin{array}{l}\text { C5: hemisection } \\
\text { left side of cord }\end{array}$ & $\begin{array}{l}\text { T1: focal cord } \\
\text { contusion with } \\
\text { small posterior } \\
\text { subdural } \\
\text { haematoma }\end{array}$ & $\begin{array}{l}\text { Left sided } \\
\text { paralysis below } \\
\text { C5; bilateral } \\
\text { anterior cord } \\
\text { syndrome in lower } \\
\text { limbs }\end{array}$ \\
\hline 2 & $\begin{array}{l}\text { Fall: extension } \\
\text { injury }\end{array}$ & $\begin{array}{l}\text { C3: central cord } \\
\text { contusion with } \\
\text { degenerative canal } \\
\text { stenosis }\end{array}$ & $\begin{array}{l}\text { C5: posterior cord } \\
\text { contusion with } \\
\text { degenerative canal } \\
\text { stenosis }\end{array}$ & $\begin{array}{l}\text { Bilateral limb } \\
\text { paralysis below } \\
\text { C4; bilateral } \\
\text { anaesthesia below } \\
\text { C7 }\end{array}$ \\
\hline 3 & $\begin{array}{l}\text { Fall: extension } \\
\text { injury }\end{array}$ & $\begin{array}{l}\text { C3: cord } \\
\text { contusion with } \\
\text { degenerative canal } \\
\text { stenosis }\end{array}$ & $\begin{array}{l}\text { C6: cord } \\
\text { contusion with } \\
\text { degenerative canal } \\
\text { stenosis }\end{array}$ & $\begin{array}{l}\text { Bilateral C3 } \\
\text { anaesthesia; } \\
\text { central cord } \\
\text { syndrome below } \\
\text { C6 }\end{array}$ \\
\hline 4 & $\begin{array}{l}\text { MVA: extension } \\
\text { injury }\end{array}$ & $\begin{array}{l}\text { C2: small anterior } \\
\text { epidural } \\
\text { haematoma }\end{array}$ & $\begin{array}{l}\text { C4: normal cord } \\
\text { with prevertebral } \\
\text { swelling }\end{array}$ & $\begin{array}{l}\text { Central cord } \\
\text { syndrome below } \\
\text { C4-complete } \\
\text { recovery }\end{array}$ \\
\hline 5 & $\begin{array}{l}\text { MVA: flexion } \\
\text { injury }\end{array}$ & $\begin{array}{l}\text { T8: complete cord } \\
\text { transection }\end{array}$ & $\begin{array}{l}\text { L1: flexion type } \\
\text { fracture and } \\
\text { dislocation }\end{array}$ & $\begin{array}{l}\text { Transverse } \\
\text { complete } \\
\text { paraplegia below } \\
\text { T8 }\end{array}$ \\
\hline 6 & $\begin{array}{l}\text { MVA: flexion } \\
\text { injury }\end{array}$ & $\begin{array}{l}\text { T9: cord contusion } \\
\text { with small } \\
\text { posterior subdural } \\
\text { haematoma }\end{array}$ & L2: burst fracture & $\begin{array}{l}\text { Transverse } \\
\text { paraplegia below } \\
\text { T10 }\end{array}$ \\
\hline 7 & $\begin{array}{l}\text { Fall: vertical } \\
\text { compress injury }\end{array}$ & $\begin{array}{l}\text { T11: cord } \\
\text { contusion }\end{array}$ & $\begin{array}{l}\text { L1: burst fracture } \\
\text { with conus } \\
\text { haematoma }\end{array}$ & $\begin{array}{l}\text { Transverse motor } \\
\text { paraplegia below } \\
\text { T12. Perineal } \\
\text { anaesthesia }\end{array}$ \\
\hline
\end{tabular}


deficit, where at least one cord segment separated the two levels; or a cord lesion at least one segment distant from the site of pathology demonstrated with imaging.

\section{Results}

Of the 71 patients (56 cervical and 15 thoracolumbar injuries), seven $(10 \%)$ had clinical and MR evidence of non-contiguous spinal injury, with more than one neurological or imaging level involved. Their clinical and MR findings are presented in Table I.

Three of these patients had MR evidence of a small local area of extramedullary haemorrhage in the absence of bone or disc injury at one of the levels (patients 1,4 and 6; Figures 1 and 2). A fourth (patient 7) also had no evidence of a causative lesion for the second spinal cord abnormality. Patient 5 had MR and radiographic evidence of a catastrophic bony injury at one level, with complete cord transection at a distant level (Figure 3). The remaining two patients had underlying degenerative cervical canal stenosis at each of the two levels involved (Figure 4).

\section{Discussion}

Prior to the introduction of MRI into the investigation of patients with spinal injuries, little was known about the specific spinal cord pathology during life, with only limited data available from postmortem studies. ${ }^{6}$ MRI has allowed categorisation of spinal cord injury by pathological type ${ }^{7}$ and has resulted in the demonstration of unsuspected spinal lesions. ${ }^{8}$

All seven patients in this series had clinical features which could not be explained on the basis of standard radiographs and computed tomography (CT). Whilst the entity of spinal cord injury without bony injury is well known, and in one large series comprised $17 \%$ of all cases, ${ }^{9}$ six of the seven patients in this series had some form of bony abnormality to explain some, although not

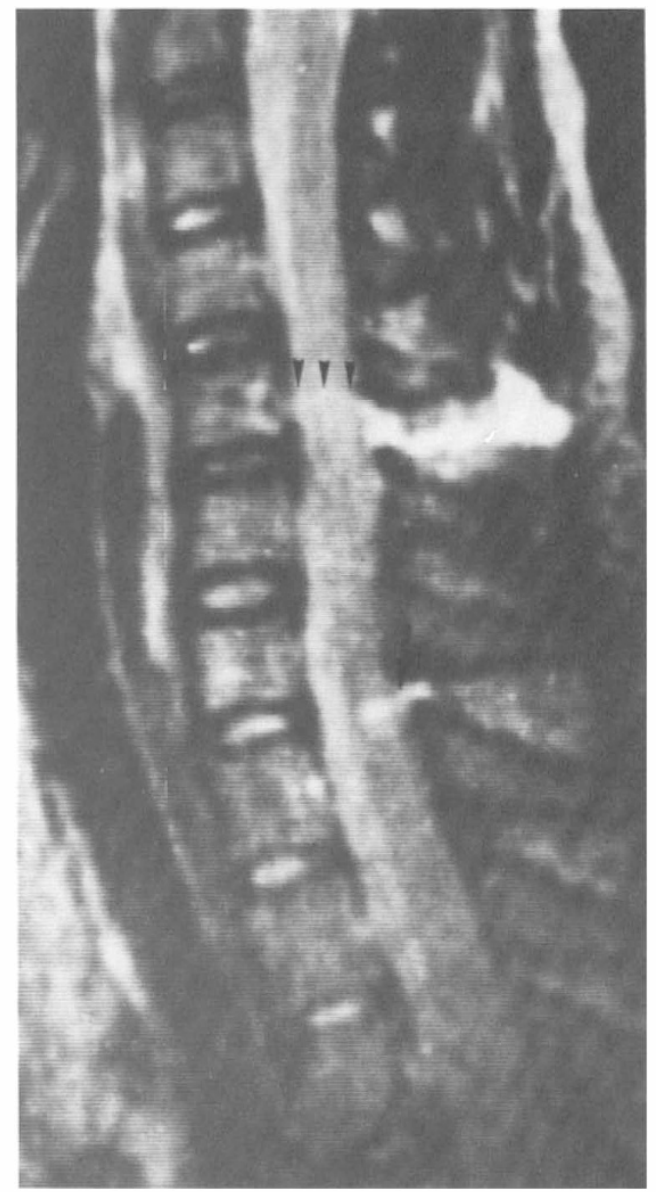

Figure 1 Partial cord transection and distant contusion (patient 1). Sagittal T2-weighted MR image in a 19 year old female presenting with left sided paralysis below C5 and bilateral motor paralysis in the lower limbs following a stab wound to the neck. Note partial cord transection at C5 (short arrowheads), and a small cord contusion at C7-T1. A small high signal area, indicating epidural haematoma is present behind the cord at the lower level (arrow).

all, of the clinical findings. In these cases, demonstration of more than one abnormal level with MRI resulted in pathological explanation of the clinical signs.

Why do patients with apparently only one level of bony injury develop a distant cord lesion? In two of the cases degenerative spinal canal stenosis was present at multiple levels, a recognised risk factor for spinal 
a

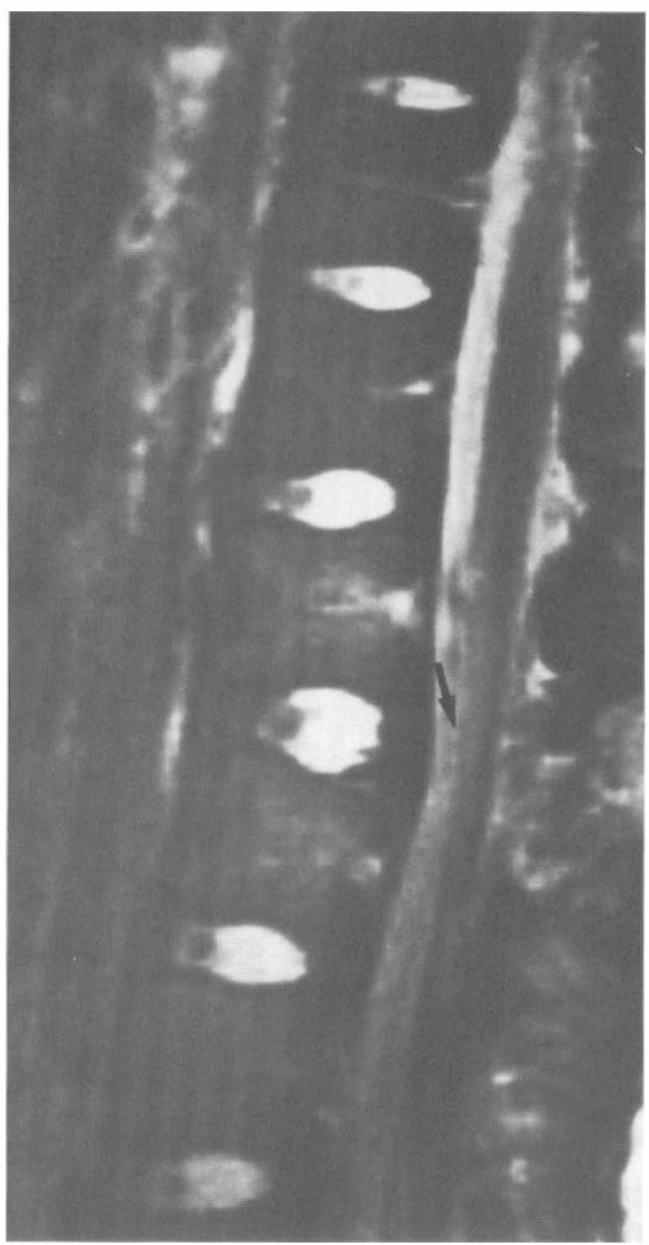

$\mathbf{b}$

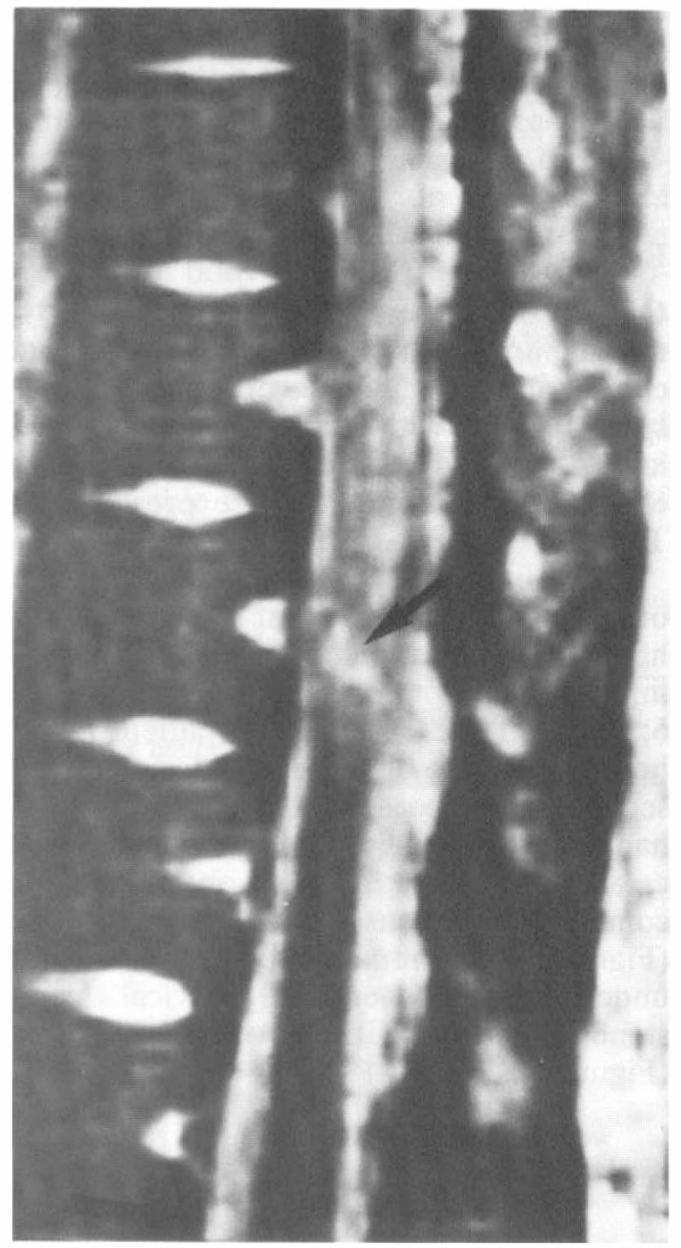

c

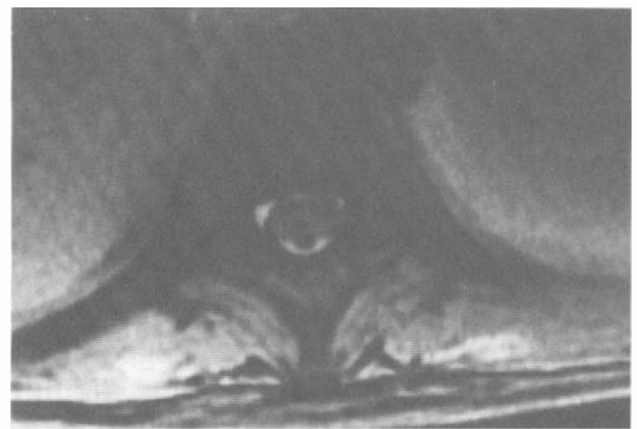

Figure 2 Cord contusion several segments above lumbar fracture (patient 6). Images of a 12 year old female presenting with paraplegia below T10 following a motor vehicle accident. (a) Sagittal T2-weighted MR image through lumbar spine shows contusion of conus medullaris (arrowed) following a fracture through posterosuperior aspect of L2 vertebral body. (b) Sagittal image through lower thoracic spine demonstrating cord contusion at T9 (arrowed). Longer area of high signal above the contusion is due to volume averaging from adjacent CSF in the spinal canal. (c) Axial image at T9. Note small posterior subdural haematoma. 


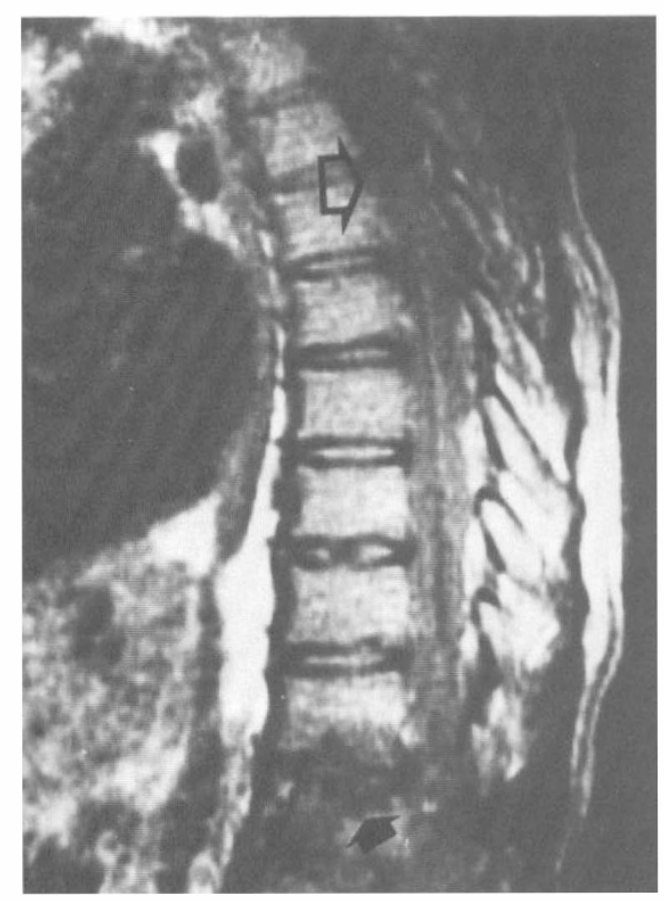

Figure 3 Complete thoracic cord transection above a lumbar injury (patient 5). Sagittal T1weighted MR image through thoracolumbar spine in a 26 year old male patient presenting with paraplegia below T8 following a motor vehicle accident resulting in a fracture/dislocation at L1 (closed arrow). Note cord abnormality at T6 (open arrow), which on other images was found to be due to cord transections.

cord injury, due to cord compression. ${ }^{10}$ Jellinger $^{2}$ considers remote cord lesions to represent the result of posttraumatic circulatory disorders. This was obviously not the case in patient 5 , where the fracture/dislocation at L1 presumably tethered the conus at this level, resulting in cord stretching 'like a string over a violin bridge'. ${ }^{11}$ Could this have been the mechanism in other patients in this series? In patient 1 who was stabbed at $\mathrm{C} 5$, the knife may have locally tethered the cord at this level, and with flexion, resulted in cord stretching. The second lesion below this was associated with local disruption of small vessels and local subdural haemorrhage (Fig 1). A similar mechanism may have applied in patient 6 , with tethering of the cauda equina by the L3 burst fracture, and the distant cord lesion at T9 due to cord stretching, and marked by local subdural haemorrhage (Fig 2). Patient 7 also had cord compression by a burst fracture with a distant cord lesion. Whilst there is undoubtedly local vascular compression at the site of bony injury, all of these patients had small solitary distant cord lesions, in contrast to patients with spinal cord ischaemia, who usually have longer segments of oedematous spinal cord. ${ }^{12}$

Spinal cord stretching is a recognised technique for the induction of experimental cord injury, ${ }^{13}$ but is not usually considered as the cause of most human spinal cord injuries, which are thought to arise from cord compression. ${ }^{2}$ The cause of the spinal cord lesion in patients without evidence of bony injury is not clearly understood, although in some cases it is considered to represent the sequel of spinal cord ischaemia. ${ }^{14}$ It is conceivable that in some of these cases, cord stretching may be the cause of cord injury, in the absence of any demonstrable cord compression.

\section{Conclusions}

Non-contiguous spinal injuries are uncommon sequelae of spinal trauma. In this study seven patients $(10 \%$ of all cord injuries) with this condition are described. In at least four of these there was radiographic and MRI evidence suggesting that the distant lesion was the sequel of cord stretching, including two patients who had small local haemorrhages adjacent to the spinal cord at the level of the second injury. Cord stretching is acknowledged as a technique for induction of experimental spinal cord injury, but has often not been considered in the past as a potential mechanism for human spinal cord injury.

\section{Acknowledgement}

We are grateful for the assistance of Dr Doug Brown, Director of Spinal Injuries, Austin Hospital, Melbourne. 
a

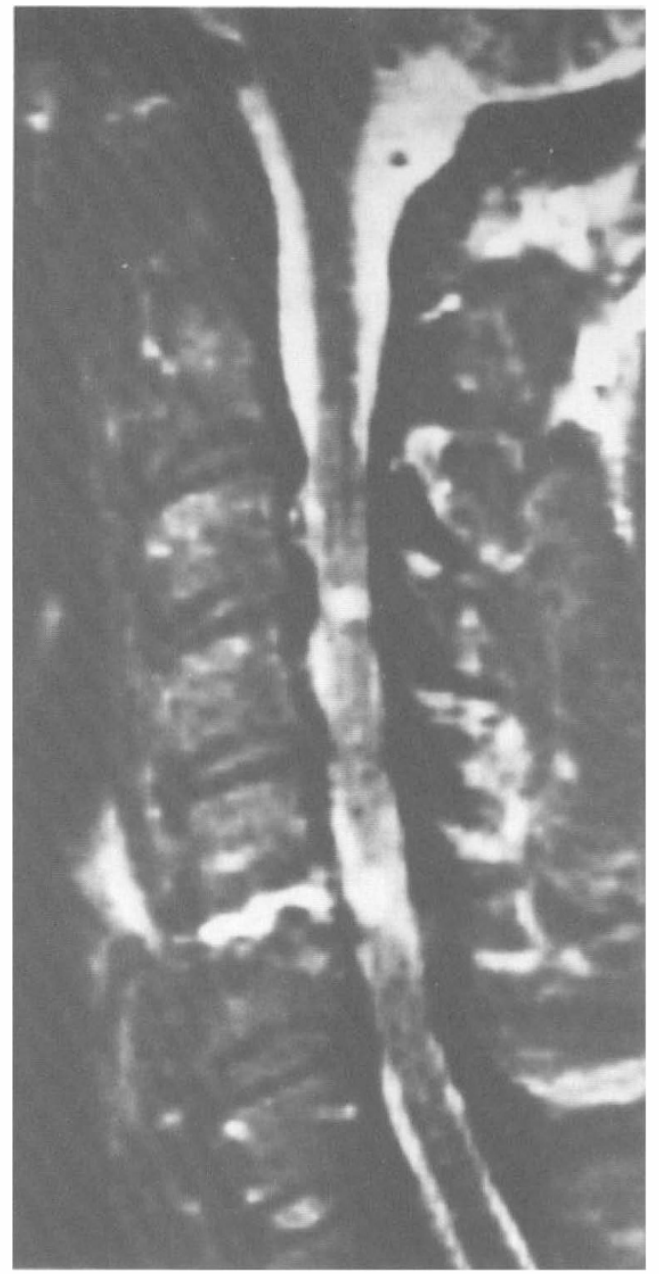

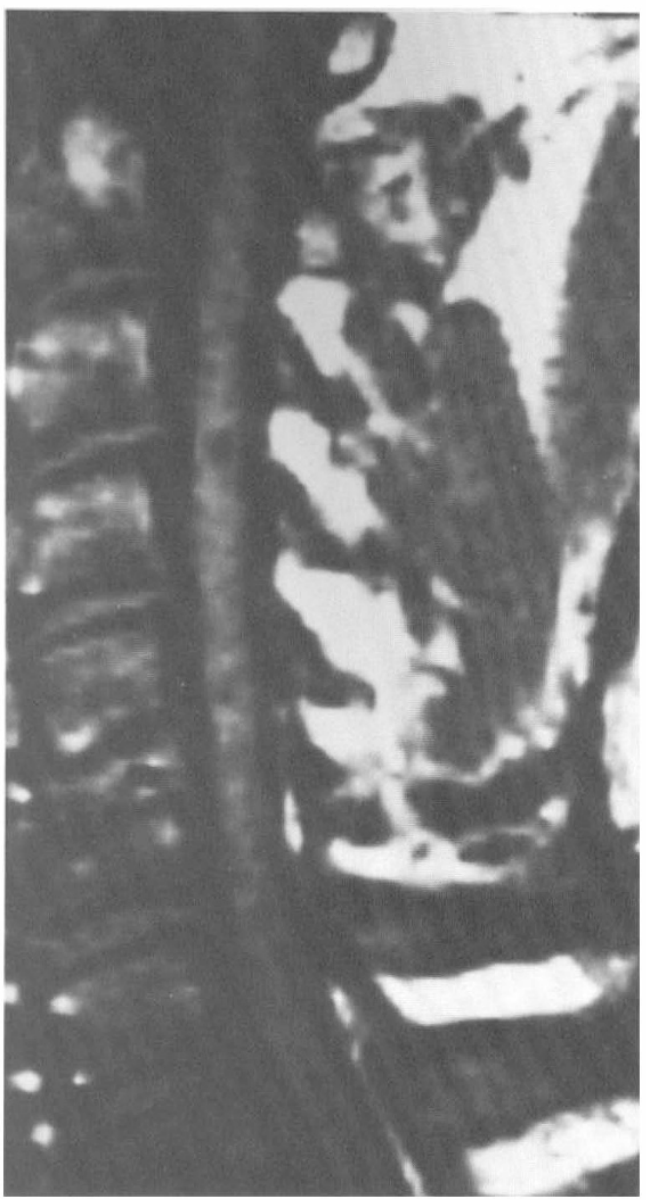

Figure 4 Separate cord contusions in multilevel canal stenosis (patient 2). Images of a 34 year old male presenting with bilateral limb paralysis below $\mathrm{C} 4$ and bilateral anaesthesia below C7. (a) Sagittal T2-weighted MR image through cervical spine demonstrates focal contusions at C3 and C5 associated with degenerative canal stenosis at both levels. (b) Sagittal T1-weighted image 6 months later. Small posttraumatic cord cysts have developed at each level, indicating that the original lesions were due to recent trauma (see reference 5).

\section{References}

1 Jellinger K (1976) Neuropathology of cord injuries. In: Vinken PJ, Bruyn GW, editors. Handbook of Clinical Neurology. Vol 25. North Holland, Amsterdam: 43-123.

2 Jellinger K (1991) Pathology of spinal cord trauma. In: Errico TJ, Bauer RD, Waugh T, editors. Spinal Trauma. J B Lippincott, Philadelphia: 455-495.

3 Yashon D (1978) Pathogenesis of spinal cord injury. Orthop Clin North Am 23: 247-261.

4 Flanders AE, Schaefer MD, Doan HT et al (1990) Acute cervical spine trauma: correlation of MR imaging findings with degree of neurologic deficit. Radiology 177: 25-33.

5 Silberstein M, Hennessy O (1993) Implications of focal spinal cord lesions following trauma: evaluation with magnetic resonance imaging. Paraplegia 31: 160-167.

6 Kakulas BA (1984) Pathology of spinal injuries. Cent Nerv Syst Trauma 1: 117-126. 
7 Schouman Claeys E, Frija G, Cuenod CA (1990) MR imaging of acute spinal cord injury: results of an experimental study in dogs. AJNR 11: 969-965.

8 Sett P, Crockard HA (1991) The value of magnetic resonance imaging (MRI) in the follow-up management of spinal injury. Paraplegia 26: 386-410.

9 Riggins RS, Kraus JF (1977) The risk of neurologic damage with fractures of the vertebrae. J Trauma 17: 126-133.

10 Regenbogen VS, Rogers, LF, Atlas SW, Kim KS (1986) Cervical spinal cord injuries in patients with cervical spondylosis. AJR 146: 277-284.

11 Braakman R, Penning L (1976) Injuries of the cervical spine. In: Vinken PJ, Bruyn GW, editors. Handbook of Clinical Neurology. Vol 25. North Holland, Amsterdam: 43-123.

12 Yuh WT, Marsh EE, Wang AK et al (1992) MR imaging of spinal cord and vertebral body infarction. AJNR 13: $145-154$.

13 Dohrmann GJ (1972) Experimental spinal cord trauma: a historical review. Arch Neurol 27: 468-474.

14 Davis PC, Reisner A, Hudgins PA et al (1993) Spinal injuries in children: role of MR. AJNR 14: $607-617$. 